\title{
Tier 2 Social and Emotional Learning Interventions of a Multi-Tier System of Support: Literature Review
}

\author{
Faisal Aldawsari \\ Professor Assistant, Phd, Prince Sattam Bin Abdulaziz University \\ Email: f.aldawasri@psau.edu.sa \\ https://orcid.org/0000-0003-3788-7365
}

\begin{abstract}
There are many students who face barriers and difficulties to display social emotional learning competencies. As result of lacking these skills, students become less connected to school as they proceed from elementary to middle to high school and negatively impact their academic performance, behavior, and health. Research shows that small group instruction is highly effective in helping students master essential skills and tasks. The purpose of this paper is to review social and emotional learning interventions at Tier 2 of a Multi-Tier System of Support (MTSS). The secondary intervention tier utilizes targeted interventions in small groups identified by support team and then employ them by using effective strategies that directly target a skill deficit. This paper includes a review of evidence-based practices for improving social-emotional outcomes and interventions for behavioral problems.
\end{abstract} Keywords: social-emotional learning, multi-tier system of support, tier 2, and evidence-based practice.

DOI: $10.7176 / \mathrm{JEP} / 12-36-02$

Publication date: December $31^{\text {st }} 2021$

\section{Introduction}

There is increasing acknowledgement among practitioners and researchers that pupil's success relies not only on accomplishment of core academic subjects but also learning intrapersonal and interpersonal competencies. The field of education has made considerable developments and improvements in school-based interventions such as social emotional learning programs (Merrell, 2010). Developing these skills should begin in an early stage and continue throughout the childhood and adolescence affected by relationships, social environments, informal interactions and structured programs (Jones \& Bouffard, 2012). Zins and Elias (2006) defined social emotional learning as "the process of acquiring and effectively applying the knowledge, attitudes, and skills necessary to recognize and manage emotions; developing caring and concern for others; making responsible decisions; establishing positive relationships; and handling challenging situations capably" (p. 1). The purpose of this paper is to review social and emotional learning interventions at Tier 2 of a Multi-Tier System of Support (MTSS).

The Every Student Succeeds Act (ESSA) provides teachers an opportunity to recognize the significance of developing the students' social-emotional skills as tools for academics and life (Ferguson, 2016). According to ESSA, States are required to incorporate at least one "nonacademic" indicator of the student's level into their accountability systems, establish learning environments and enhance students' effective learning skills that are essential for the school readiness and academic success (Ferguson, 2016). In addition, the act emphasizes on the use of evidence-based interventions and provide flexibility to States and school districts regarding the use of federal funds, including funds that could be used to enhance social and emotional learning (Grant, Hamilton, Wrabel, Gomez, Whitaker, Leschitz, \& Harris, 2017).

Regrettably, many students have difficulties to display social emotional learning competencies (Durlak, Weissberg, Dymnicki, Taylor, \& Schellinger, 2011). According to U.S. Department of Education, educators continue to struggle to address the needs of students, who have social, emotional, or behavioral difficulties and problems (Saeki et al., 2011). As a consequence of lacking these skills, students become less connected to school as they proceed from elementary to middle to high school and negatively impact their academic performance, behavior, and health (Durlak, et al., 2011). Saeki et al. (2011) indicated that social emotional and behavioral issues are highly linked to poor school related outcomes. A report of recent research pointed out that children who attend kindergarten with underdeveloped social and behavioral skills, are more likely to be retained in grade level, identified for special education services, and suspended or expelled from school (Bettencourt, Gross, \& Ho, 2016). In addition, a very tiny amount of time and energy is spent on serving a small number of individuals with socialemotional and behavior problems (Saeki et al., 2011).

Research elucidates that an emphasis on social-emotional learning can enhance, rather than detract from, schools' core missions of improving academic achievement and attainment (Osher et al., 2016). Therefore, Multitiered systems of support (MTSS) seek to address and target students who exhibit social, emotional, and behavioral problems by implementing evidence-based practices (EBPs) (Cook, Lyon, Kubergovic, Wright, \& Zhang, 2015). MTSS is a proactive, prevention-oriented service delivery framework that aims to meet all students' needs through the implementation of a continuum of EBPs by data-driven decision making (Cook, Lyon, Kubergovic, Wright, \& Zhang, 2015). Students with emotional and behavioral problems are in need for MTSS because of the challenges 
they encounter due to the severity of their behavioral and academic problems (Benner, Kutash, Nelson, \& Fisher, 2013).

MTSS like positive behavior interventions and supports (PBIS) and response-to-intervention (RTI) are used and adopted by schools in order to assist students to meet their needs (Bruhn, Lane, \& Hirsch, 2014). Both models directly address the academic, social, emotional, and behavioral development of children and youth, from early childhood through adolescence and represent the foundation of a comprehensive MTSS framework (Averill, Rinaldi \& Collaborative, 2011). These frameworks promote positive academic and behavioral outcomes related to students and provide safe and affirmative school climate (Ziomek-Daigle, Goodman-Scott, Cavin \& Donohue, 2016).

Social and emotional learning interventions support student social and emotional development through explicit instruction, purposefully strengthening cognitive processes, emotional competencies, and social and interpersonal skills needed for successful self-regulation (Smith, Poling, \& Worth, 2018). MTSS comprises of a three-tiered approach, including tier 1, tier 2, and tier 3 (Bruhn, Lane, \& Hirsch, 2014). At each tier, students who are slow or making inadequate progress will be moved to the next tier level in order to receive more intensive instruction and data are collected at each tier to monitor progress (Bradley et al., 2007). To illustrate, the student who started in tier 1 and was not able to respond to the intervention, will move to tier 2 interventions to receive more intensive levels of instruction and intervention combined with more frequent progress monitoring (Hughes, \& Dexter, 2011). It is also important to obtain parental consent for students who are identified to receive private tutoring and a more intense intervention.

\section{Tier 2 Interventions}

Tier 2 or as also known the secondary intervention tier comprises of approximately $15 \%$ of the student population (Berkeley, Bender, Gregg Peaster, \& Saunders, 2009). In addition, tier 2 uses targeted interventions in small groups. Research shows that small group instruction is highly effective in helping students master essential skills and tasks (Buffum, Mattos, \& Weber, 2010). According to Truscott et al. (2005), the secondary interventions tier can also be private tutoring by special education teacher or general education teacher. Most interventions in this tier are delivered by using strategies that directly target a skill deficit (Buffum, Mattos, \& Weber, 2010). Tier 2's goals are to provide further attention, narrower concentration, greater support, and more opportunities to practice (Greenwood et al., 2011). Another goal is also to decrease current cases of problem behavior and/or academic failure to prohibit student issues from increasing or escalating to an intensity that requires individualized planning (Mitchell, Stormont \& Gage, 2011). At tier 2, social-emotional and behavioral programs typically direct considerable attention on teaching school-wide behavioral expectations to students who are at-risk in small segments (Jimerson, Burns, \& VanDerHeyden, 2015).

It is guided by supporting evidence and instructional approaches that are embedded to meet the academic and nonacademic needs or goals of students in small segments or individually. Tier 2 interventions are utilized similarly across students who display prevalent behavior issues (e.g., repeatedly tardy, in classroom disruptions, organizational problems, social skills deficits), and who may respond to similar interventions (Campbell, Rodriguez, Anderson, \& Barnes, 2013). Mitchell, Stormont and Gage (2011) indicated that hallmark features of Tier 2 level consists of rapid access to intervention, low-effort teacher implementation facilitated by a team-based approach, progress monitoring to determine the effectiveness of the intervention and the need for making decision regarding the intervention.

By implementing tier 2, the student support team should use ongoing formative assessment to identify pupils who require additional support and specific needs (Buffum, Mattos, \& Weber, 2010). There should be a standard assessment plan and clear criteria for entering and exiting students from the secondary intervention tier (Greenwood et al., 2011). The types of support in this tier have to be designed to rapidly screen for and target students who are in need for extra instruction or services to get back on track. The support team of the student has to identify the student's needs of tier 2 interventions in order to facilitate the implementation of the intervention (Ziomek-Daigle, Goodman-Scott, Cavin \& Donohue, 2016). The team is also responsible to make decisions regarding fading or ending the intervention once the student maintains positive progress (Ziomek-Daigle, Goodman-Scott, Cavin \& Donohue, 2016).

Buffum, Mattos, and Weber (2010) indicated that for tier 2 effective interventions, they should be timely structured and mandatory as well as they have to focus the cause of a student's struggles rather than on a symptom. Moreover, these researchers highly recommend that trained and qualified educators should administer interventions. They also emphasize on using universal screening data to identify students lacking the prerequisite skills for a fundamental standard before providing the designated intervention. In the secondary interventions tier, students are identified by whether universal screening or educators who have experiences of social, emotional, or behavioral difficulties that their students exhibit (Wilson \& Lipsey, 2007). 


\section{Evidence Based Practice For Improving Social Emotional Outcomes}

There is an increased attention of the use of scientifically based behavioral interventions to prevent the development of problem behaviors and address the need of students with behavioral challenges (Jimerson, Burns, \& VanDerHeyden, 2015). The outcomes show improvement in social-behavioral as well as academics when interventions based empirical evidence are implemented with fidelity and integrity. According to Horner, Sugai,and Anderson (2010), the majority of research based MTSS applications for behavioral challenges are conceptualized and implemented within a PBIS or a school-wide positive behavior support (SWPBS) framework. Fundamental evidence supports the utility of PBIS or SWPBS as an effective MTSS approach to prevent social emotional-behavioral challenges, to close the gap between identification and intervention and to enhance success for all learners.

Grant et al. (2017) stated that the secondary intervention tier must come from rigorous quasi-experimental research and studies; which approximates experimental studies by specifying a comparison group that is similar to the intervention group participants on observed pre-intervention characteristics. Within special education, methods of single subject case are accepted and valid designs to demonstrate intervention influences, and researchers can control extraneous factors and clarify the relationships between dependent variables and independent variables (Mitchell, Stormont, \& Gage, 2011). According to ESSA standards, the quality of studies in tier 2 contains statistically significant, positive results from studies that determined baseline equivalence between the groups in the analytic sample (Grant et al., 2017). These studies include non-randomly assigned individuals or groups of participants to the social emotional learning intervention or comparison group or randomly assigned participants or groups to social- emotional learning or comparator interventions but had high attrition.

\section{Common Interventions for Behavioral Problems in Tier 2}

The strategies of secondary intervention level are provided for individuals who require more structured behavioral interventions, more frequent and contingent behavior feedback, and/ or more active supervision and monitoring by educators (Jimerson, Burns, \& VanDerHeyden, 2015). Durlak and colleagues (2011) conducted a meta-analysis of school-based universal interventions and found there were four components for the most effective programs of enhancing students' social and emotional learning outcomes. These components include sequenced activities lead to learn skills in a coordinated and connected way, active forms of learning, focused instruction to develop one or more social skills, and explicit lessons that target specific skills.

Particular intervention strategies and methods that have empirical support are proposed for use as tier 2 interventions, including modeling and guided practice strategies, coaching strategies, supportive and corrective feedback, peer-mediated strategies, and self-monitoring strategies (Greenwood et al. 2011; Jimerson, Burns, \& VanDerHeyden, 2015). Educators, who are going to implement these strategies, have to follow specific steps and procedures to assure they are conducted in a systematic manner. The important steps when implementing modeling and guided practice include determining the skill or competency that most benefit the student, modeling the target behavior for the child multiple times, giving chances for them to practice the target behavior, providing expanded experiences in which the skill or competence can be applied and used successfully, and presenting specific and corrective feedback by stating or describing explicitly how and why the behavior was appropriate or inappropriate.

Peer-mediated Instructions (peer proximity, peer prompting, peer initiation Peer-buddy interventions, and peer tutoring) also have considerable and empirical support for tier 2 (Greenwood et al. 2011; Latz et al. 2009). Peer-mediated approaches incorporate the student's peers as models or instructors to enhance his/her development of emotional-social competencies. These strategies provide alternative learning opportunities such as respond to aggression and conflict, and help to complete assignments. Other common behavioral interventions of tier 2 also include existing additional support programs that require minimal personnel time to implement such as check-in, check-out and also known as the behavior education program (EPD), check \& connect, and first step to success (Hawken, Vincent, \& Schumann, 2008).

The Check in/ Check out (CICO) or Behavior Education Program (BEP) was developed to reduce problem behavior that target secondary level students (Filter et al. 2007). The purpose of CICO intervention is to enhance antecedent prompts for appropriate behavior, increase contingent adult feedback, improve the daily structure for students during school day, and increase feedback to families about the child's behavior. According to Simonsen, Myers, and Briere (2011) experimental single-subject studies' results indicate the effectiveness of CICO interventions with different participants' ages and school settings. At the beginning of the day, schools' mentors review the behavioral expectations with the target students (check in) including possible solutions to respond to any potential obstacles (Horner, Sugai, \& Anderson, 2010; Swoszowski, McDaniel, Jolivette, \& Melius, 2013). Students carry around a point card that provides opportunities for mentors' behavioral feedback throughout the day to help students practice the desirable behavior, and review their goal for getting daily points. At the end of the day, students give the card point to portents to sign and return it to the school (check-out).

Check \& Connect is a dropout prevention program and comprehensive model used to promote individuals' engagement with school, and it is data-driven and designed to increase personal contact and opportunities to build 
trusting relationships (Sinclair, Christenson, Lehr, \& Anderson, 2003; Hawken, Vincent, \& Schumann, 2008). The approach allows students and an adult in the school to "check in" on behavioral barriers and "connect" by creating a caring relationship, containing aspects of psychological engagement, behavioral engagement and cognitive engagement (Kern, George, \& Weist, 2016). Check \& Connect emphasizes the school and home connection through trained school-based mentors (Bradshaw, Pas, Debnam, \& Lindstrom Johnson, 2015; Yong, \& Cheney, 2013).

First Step to Success (FSS) is an effective secondary-level intervention to reduce the number of psychosocial risk factors and improve the overall well-being and adjustment of young individuals at risk (Ozdemir, 2011). FSS is an early intervention that is designed for at-risk primary level, elementary school students who display clear signs of emerging externalizing behavior problem (Frey et al., 2013). According to Seeley et al. (2017) FSS is also identified as an intervention for preschool or Head Start classroom use, and teachers can utilize it as a part of their classroom routine. FSS is a school-home intervention that consists of three components (Sumi et al., 2013). They are the universal screening, classroom-based intervention, and in-home parent education.

A key factor for successful social and emotional interventions is the implementation fidelity and quality by measuring and evaluating its influence in relation to the outcomes (Zins and Elias, 2006). Schools should adequately work to implement interventions with fidelity for social behavior in order to acquire the desired outcomes (Hawken, Vincent, \& Schumann, 2008). It is important that school personnel select appropriate goals and focus on changing behavior that students are capable of learning the keystone of social-emotional and behavioral competencies which have powerful influences on behavioral adjustment such as following directions, demonstrating self-control, making positive comments toward others, joining others in play or small groups. Strategies selected to achieve goals should be simple, uncomplicated and easy to follow in order to result in high integrity and efficacy level of the intervention along with interveners scaffolding and supporting the behavior appropriately (Jimerson, Burns, \& VanDerHeyden, 2015).

\section{Conclusion}

Social emotional and behavioral issues that students suffer from are tightly connected with a variety of poor schoolrelated outcomes. These problems result of lacking these skills, students become less connected to school as they proceed from elementary to middle to high school and negatively impact their academic performance, behavior, and health. As this research indicated that a small amount of students receive assistance regarding the enhancement of social-emotional and behavior skills. Many studies and research's views as previously presented in this study indicate that social-emotional learning competences are important for students to acquire since they improve cognitive processes and social and interpersonal skills needed for successful self-regulation as well as improving academic achievement and attainment.

MTSS as a systemic and ongoing improvement framework seek to address and target students who exhibit social, emotional, and behavioral problems. MTSS include three tiers (tier 1, tier 2, and tier 3) and those who are making inadequate progress will be moved to the next tier level. Specifically, this literature discussed social and emotional learning interventions for Tier 2 of MTSS. The secondary intervention tier utilize targeted interventions in small groups identified by support team and then employ them by using strategies that directly target a skill deficit. It is important to use interventions that are scientifically evidence-based practices in order to increase social-emotional outcomes as the research show. Explicit strategies, peer-mediated instructions, as well as checkin, check-out, check \& connect, and first step to success are effective interventions to be used for the secondary level interventions. Finally, fidelity and integrity must be well designed and implemented to gain positive outcomes.

\section{References}

Averill, O. H., Rinaldi, C., \& Collaborative, U. S. E. L. (2011). Multi-tier System of Supports (MTSS). District Administration, 48(8), 91-95.

Bayat, M., Mindes, G., \& Covitt, S. (2010). What does RTI (response to intervention) look like in preschool?. Early Childhood Education Journal, 37(6), 493-500.

Bear, G. G., \& Minke, K. M. (2006). Children's needs III: Development, prevention, and intervention. National Association of School Psychologists.

Benner, G. J., Kutash, K., Nelson, J. R., \& Fisher, M. B. (2013). Closing the achievement gap of youth with emotional and behavioral disorders through multi-tiered systems of support. Education and Treatment of Children, 36(3), 15-29.

Berkeley, S., Bender, W. N., Gregg Peaster, L., \& Saunders, L. (2009). Implementation of response to intervention: A snapshot of progress. Journal of Learning Disabilities, 42(1), 85-95.

Bettencourt, A., Gross, D., \& Ho, G. (2016). The Costly Consequences of Not Being Socially and Behaviorally Ready by Kindergarten: Associations with Grade Retention, Receipt of Academic Support Services, and Suspensions/Expulsions. Baltimore Education Research Consortium.

Bradshaw, C. P., Pas, E. T., Debnam, K. J., \& Lindstrom Johnson, S. (2015). A focus on implementation of Positive 
Behavioral Interventions and Supports (PBIS) in high schools: Associations with bullying and other indicators of school disorder. School Psychology Review, 44(4), 480-498.

Bruhn, A. L., Lane, K. L., \& Hirsch, S. E. (2014). A review of tier 2 interventions conducted within multitiered models of behavioral prevention. Journal of Emotional and Behavioral Disorders, 22(3), 171-189.

Bruhn, A. L., Lane, K. L., \& Hirsch, S. E. (2014). A review of tier 2 interventions conducted within multitiered models of behavioral prevention. Journal of Emotional and Behavioral Disorders, 22(3), 171-189.

Buffum, A., Mattos, M., \& Weber, C. (2010). The why behind RTI. Educational Leadership, 68(2).

Campbell, A., Rodriguez, B. J., Anderson, C., \& Barnes, A. (2013). Effects of a Tier 2 intervention on classroom disruptive behavior and academic engagement. Journal of curriculum and instruction, 7(1), 32-54.

Cook, C. R., Lyon, A. R., Kubergovic, D., Wright, D. B., \& Zhang, Y. (2015). A supportive beliefs intervention to facilitate the implementation of evidence-based practices within a multi-tiered system of supports. School mental health, 7(1), 49-60.

Durlak, J. A., Weissberg, R. P., Dymnicki, A. B., Taylor, R. D., \& Schellinger, K. B. (2011). The impact of enhancing students' social and emotional learning: A meta - analysis of school - based universal interventions. Child development, 82(1), 405-432.

Ferguson, M. (2016). Washington View: ESSA opens school door to social-emotional learning. Phi Delta Kappan, 97(8), 74-75.

Filter, K. J., McKenna, M. K., Benedict, E. A., Horner, R. H., Todd, A., \& Watson, J. (2007). Check in/check out: A post-hoc evaluation of an efficient, secondary-level targeted intervention for reducing problem behaviors in schools. Education and Treatment of Children, 30(1), 69-84.

Frey, A. J., Small, J., Feil, E., Seeley, J., Walker, H., \& Golly, A. (2013). The feasibility of First Step to Success with preschoolers. Children \& schools, 35(3), 171-186.

Grant, S., Hamilton, L. S., Wrabel, S. L., Gomez, C. J., Whitaker, A., Leschitz, J. T., ... \& Harris, M. (2017). Social and Emotional Learning Interventions under the Every Student Succeeds Act: Evidence Review. Research Report. RR-2133-WF. RAND Corporation.

Greenwood, C. R., Bradfield, T., Kaminski, R., Linas, M., Carta, J. J., \& Nylander, D. (2011). The response to intervention (RTI) approach in early childhood. Focus on Exceptional Children, 43(9), 1-22.

Hawken, L. S., Vincent, C. G., \& Schumann, J. (2008). Response to intervention for social behavior: Challenges and opportunities. Journal of Emotional and Behavioral Disorders, 16(4), 213-225.

Horner, R. H., Sugai, G., \& Anderson, C. M. (2010). Examining the evidence base for school-wide positive behavior support. Focus on exceptional children, 42(8), 1-14.

Hughes, C. A., \& Dexter, D. D. (2011). Response to intervention: A research-based summary. Theory into Practice, 50(1), 4-11.

Jimerson, S. R., Burns, M. K., \& VanDerHeyden, A. M. (Eds.). (2015). Handbook of response to intervention: The science and practice of multi-tiered systems of support. Springer.

Jones, S. \& Bouffard, S. (2012). Social Policy Report: Social and Emotional Learning in Schools From Programs to Strategies. Sharing Child and Youth Development Knowledge 26(4), 1-31.

Kern, L., George, M. P., \& Weist, M. D. (2016). Supporting students with emotional and behavioral problems. Baltimore, Maryland: Brookes.

Maras, M. A., Thompson, A. M., Lewis, C., Thornburg, K., \& Hawks, J. (2015). Developing a tiered response model for social-emotional learning through interdisciplinary collaboration. Journal of Educational and Psychological Consultation, 25(2-3), 198-223.

Merrell, K. (2010). Linking prevention science and social and emotional learning: The Oregon Resiliency Project. Psychology in the Schools, 47, 55-70

Mitchell, B. S., Stormont, M., \& Gage, N. A. (2011). Tier two interventions implemented within the context of a tiered prevention framework. Behavioral disorders, 36(4), 241-261.

Osher, D., Kidron, Y., Brackett, M., Dymnicki, A., Jones, S., \& Weissberg, R. P. (2016). Advancing the science and practice of social and emotional learning: Looking back and moving forward. Review of Research in Education, 40(1), 644-681.

Ozdemir, S. (2011). The effects of the first step to success program on academic engagement behaviors of Turkish students with attention-deficit/hyperactivity disorder. Journal of Positive Behavior Interventions, 13(3), 168177.

Payton, J., Weissberg, R. P., Durlak, J. A., Dymnicki, A. B., Taylor, R. D., Schellinger, K. B., \& Pachan, M. (2008). The Positive Impact of Social and Emotional Learning for Kindergarten to Eighth-Grade Students: Findings from Three Scientific Reviews. Technical Report. Collaborative for Academic, Social, and Emotional Learning (NJ1).

Saeki, E., Jimerson, S. R., Earhart, J., Hart, S. R., Renshaw, T., Singh, R. D., \& Stewart, K. (2011). Response to intervention (RtI) in the social, emotional, and behavioral domains: Current challenges and emerging possibilities. Contemporary School Psychology: Formerly" The California School Psychologist", 15(1), 43- 
52.

Seeley, J. R., Small, J. W., Feil, E. G., Frey, A. J., Walker, H. M., Golly, A., \& Forness, S. R. (2017). Effects of the first step to success intervention on preschoolers with disruptive behavior and comorbid anxiety problems. School Mental Health, 1-11.

Simonsen, B., Myers, D., \& Briere III, D. E. (2011). Comparing a behavioral check-in/check-out (CICO) intervention to standard practice in an urban middle school setting using an experimental group design. Journal of Positive Behavior Interventions, 13(1), 31-48.

Sinclair, M. F., Christenson, S. L., Lehr, C. A., \& Anderson, A. R. (2003). Facilitating student engagement: Lessons learned from Check \& Connect longitudinal studies. The California School Psychologist, 8(1), 2941.

Smith, S. W., Poling, D. V., \& Worth, M. R. (2018). Intensive Intervention for Students with Emotional and Behavioral Disorders. Learning Disabilities Research \& Practice, 33(3), 168-175.

Sumi, W. C., Woodbridge, M. W., Javitz, H. S., Thornton, S. P., Wagner, M., Rouspil, K., ... \& Small, J. W. (2013). Assessing the effectiveness of First Step to Success: Are short-term results the first step to long-term behavioral improvements?. Journal of Emotional and Behavioral Disorders, 21(1), 66-78.

Swoszowski, N. C., McDaniel, S. C., Jolivette, K., \& Melius, P. (2013). The effects of tier II check-in/check-out including adaptation for non-responders on the off-task behavior of elementary students in a residential setting. Education and Treatment of Children, 36(3), 63-79.

Wilson, S. J., \& Lipsey, M. W. (2007). School-based interventions for aggressive and disruptive behavior: Update of a meta-analysis. American journal of preventive medicine, 33(2), S130-S143.

Yong, M., \& Cheney, D. A. (2013). Essential features of tier 2 social-behavioral interventions. Psychology in the Schools, 50(8), 844-861.

Ziomek-Daigle, J., Goodman-Scott, E., Cavin, J., \& Donohue, P. (2016). Integrating a multi-tiered system of supports with comprehensive school counseling programs. The Professional Counselor, 6(3). 